\title{
Efficiency of the chimney effect controlling radon levels indoor
}

\author{
Britt Haker Høegh ${ }^{1, *}$, and Torben Valdbjørn Rasmussen ${ }^{2}$ \\ ${ }^{1}$ Danish Technological Institute, 2630 Taastrup, Denmark \\ ${ }^{2}$ Danish Building Research Institute, SBi, Aalborg University, 2450 Copenhagen, Denmark
}

\begin{abstract}
According to the WHO the radioactive gas radon must be controlled indoors. E.g. by naturally driven suction systems based on thermal buoyancy, also denoted the chimney effect, which exploits the difference of indoor- and outdoor temperature to lower radon levels indoor. This paper presents four case studies showing that the efficiency of such systems to control radon level indoors varies, as the outdoor temperature varies throughout the year. The chimney effect was the driving force in the four single-family houses used as case studies. In two cases it was used to increase the indoor air change rate to dilute the radon concentration indoor, in one case it was used to drive a suction system under the ground slab to prevent radon from infiltrating through the ground slab, and in one case both techniques were used in combination. Measurements showed a correlation between a low radon level indoors and an increased difference between the indoor- and outdoor temperature, with the highest temperature indoor. Likely, the temperature difference can provide the needed suction in such systems. Without this driving force - out of the heating season - an increase of the indoor radon level was seen to occur. The needed suction to lower the radon level indoor did not occur in all cases. However, the efficiency of the system was seen to vary throughout the year, and was limited in periods with little difference between the indoor- and the outdoor temperature. Such needs to be taken into account, when the effect of naturally driven suction systems to reduce the radon level indoor are evaluated.
\end{abstract}

\section{Introduction}

According to the WHO's recommendations the reference level for the concentration of radon indoor in Denmark were tightened in 2010 to $100 \mathrm{~Bq} / \mathrm{m}^{3}$. The reference level is mandatory for buildings constructed after 2010 and a recommended level for buildings constructed before 2010. The driving force for radon seeping into the indoor air is generally higher during the heating season than out of the heating season [1]. Partly due to less natural ventilation through opening of doors and windows. Partly because thermal buoyancy of heated indoor air reduces the pressure above the ground slab, which increases the infiltration of radon from the ground underneath the building. Not to underestimate the

*Corresponding author: brh@dti.dk 
radon level indoor, it is generally measured in the heating season [1]. Furthermore, radon levels indoor are varying significantly over time. Thus, it is recommended to estimate the mean year value of the indoor radon level by carrying out long-term measurements $(>2$ month).

To reduce radon levels indoor there are three basic concepts [2]: Air tightening building constructions towards the ground, dilution of indoor air with outdoor air (hereafter: dilution systems), as outdoor air in Denmark has a radon content of approximately $5 \mathrm{~Bq} / \mathrm{m}^{3}$ [1], or removal of radon from underneath the building by introducing suction under the ground slab (hereafter: suction systems). For both dilution and suction systems, thermal buoyancy in chimneys can be used as a natural driving force and thus provide energy neutral systems to reduce the radon level indoor. The driving force of this chimney effect is the temperature difference between indoor- and outdoor air, with a higher temperature indoor. Hence, we anticipated a varying effect of these systems during the year with the highest effect contrary to generally seen circumstances - in the heating season, and less effect out of the heating season. To investigate, if the anticipation is correct, four case studies using naturally driven dilution and/or suction systems were followed.

\section{Building description}

Four case studies were part of the investigation. The case study denoted $\mathrm{G}$ and $\mathrm{H}$ were provided with a dilution system, case study $M$ was provided with a suction system and case study R was provided with a combination of the two systems. In some cases, supplementary measures were implemented.

Case study $\mathrm{G}$ is a detached $1 \frac{1}{2}$ story one-family house constructed in 1935 with full basement. Originally the radon concentration was measured to be $194 \mathrm{~Bq} / \mathrm{m}^{3}$ in the basement and $154 \mathrm{~Bq} / \mathrm{m}^{3}$ on the ground floor. A dilution system was established in an existing, 3 stories high chimney used as exhaust channel, allowing the chimney effect and the draft of wind above the chimney top to suck indoor air out of the basement of the building. Make-up air was provided through outdoor air vents placed in exterior walls in each room in the basement, Figure 1 (left). Additionally, a door was established to separate the basement from the $2 \frac{1}{2}$ stories stairwell.
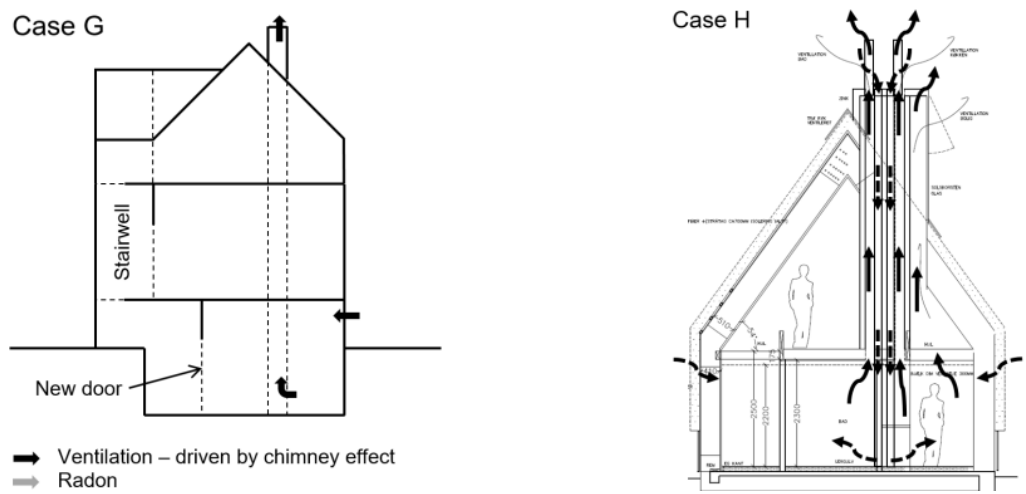

Fig. 1. Case study G: Dilution system with ventilation flow (black arrows). Case study H: Dilution system with exhaust air (black arrows) and fresh air (dashed arrows).

Case study $\mathrm{H}$ is a detached $1 \frac{1}{2}$ story house constructed in 2015 with a slab on ground of unburnt clay on a capillary breaking layer of foam glass granulate. A $1 \frac{1}{2}$ story chimney was installed with both exhaust channels for indoor air and inlet channels for outdoor air. In addition, an exhaust vent was placed near the building's ridge and inlet of outdoor air 
through vents were placed in exterior walls in each room, Figure 1 (right). As in case G the dilution system was based on the chimney effect and the draft of wind above the chimney top, driving indoor air out and outdoor air in.

Case study $\mathrm{M}$ is a detached one story single family brickhouse constructed in the late $19^{\text {th }}$ century with a stone foundation. In 2006-2009 the original floor was replaced with a concrete slab on ground on top of a layer of thermal insulation and a capillary breaking layer. The house is heated partially by floor heating and partially by radiators. The heating system is placed in the scullery, an extension to the house. The pipes are laid in the capillary breaking layer under the concrete slab. Originally the radon concentration was measured to be approximately $180 \mathrm{~Bq} / \mathrm{m}^{3}$ in both the scullery and the living room. A suction system was installed in the capillary breaking layer by connecting the holes for the pipework to the approximately $4 \mathrm{~m}$ high chimney, Figure 2.

Case study $\mathrm{R}$ is a detached $1 \frac{1}{2}$ story single family brick house with full basement. The original ground slab was of brick/concrete on clay ground. In one of the rooms in the basement (a home office) a new concrete slab on ground was installed in 1989, placed on top of a layer of thermal insulation and a capillary breaking layer of aerated clay pellets. Originally the radon concentration was measured to be $640 \mathrm{~Bq} / \mathrm{m}^{3}$ in the office, $263 \mathrm{~Bq} / \mathrm{m}^{3}$ in the depot in the basement and $172 \mathrm{~Bq} / \mathrm{m}^{3}$ in the kitchen on the ground floor. As in case study $\mathrm{G}$ a dilution system, based on the chimney effect and the draft of wind above the chimney top, was installed by using the existing $3 \frac{1}{2}$ stories high chimney as exhaust channel. Make-up air was provided through outdoor air vents placed in the exterior walls in each room in the basement. In addition, a suction system was established under the office in the basement with a separate exhaust pipe through the existing chimney, that is hosting the exhaust air of the dilution system, Figure 2. Supplementary the plaster in the basement was refurbished, in order to improve the tightness of the outer walls towards the ground.
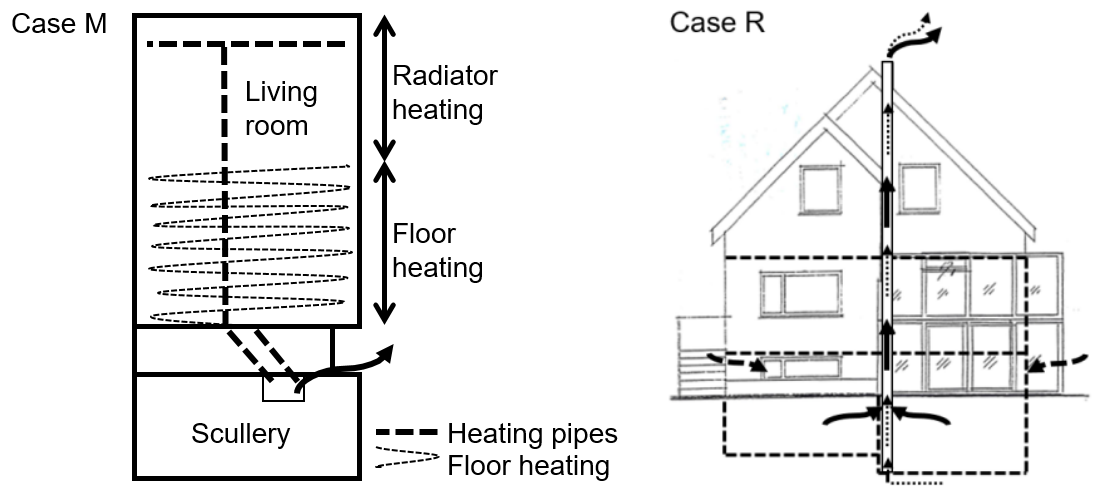

Fig. 2. Case study M: Suction system along heating pipes (wide dashed line). Case study R: Suction system (narrow dashed arrows) and dilution system with exhaust air (black arrows) and fresh air (wide dashed arrows).

\section{Measuring program}

The radon concentration was measured with closed dosimeters from MRM in Sweden and temperature logged with Trotec, BL30, logging once an hour. Measurement points were placed in one to two rooms over the ground slab (respectively basement or ground floor) and in houses with basement a supplementary measurement point was placed on the ground floor. 
Table 1. Measurement periods (dd/mm) in 2016 and duration (days) in parentheses.

\begin{tabular}{|l|c|c|c|c|}
\hline & Case G & Case H & Case M & Case R \\
\hline 1. Period & $22 / 01-24 / 04(93 d)$ & $14 / 01-17 / 05(125 d)$ & $19 / 01-27 / 04(99 d)$ & $22 / 01-24 / 04(93 d) *$ \\
\hline 2. Period & $25 / 05-21 / 07(57 d)$ & $25 / 05-11 / 08(79 d) * *$ & $30 / 05-11 / 08(74 d)$ & $25 / 05-21 / 07(57 d)$ \\
\hline 3. Period & $21 / 07-25 / 10(97 d)$ & $11 / 08-31 / 10(82 d)$ & $11 / 08-26 / 10(77 d)$ & $21 / 07-25 / 10(97 d)$ \\
\hline
\end{tabular}

* Lack of temperature measurement from basement, deposit in period 1.

** Exhaust vents partly closed in period 2.

\section{Results}

The results of each case study are presented in Figure 3. The graphs show for each period the measured average temperature difference between the indoor- and the outdoor air shown on the $\mathrm{x}$-axis and the measured average radon concentration is shown on the $\mathrm{y}$ axis. A grey shadow behind the data points indicate the uncertainty of the laboratory radon analysis. Raw data can be found in [3].
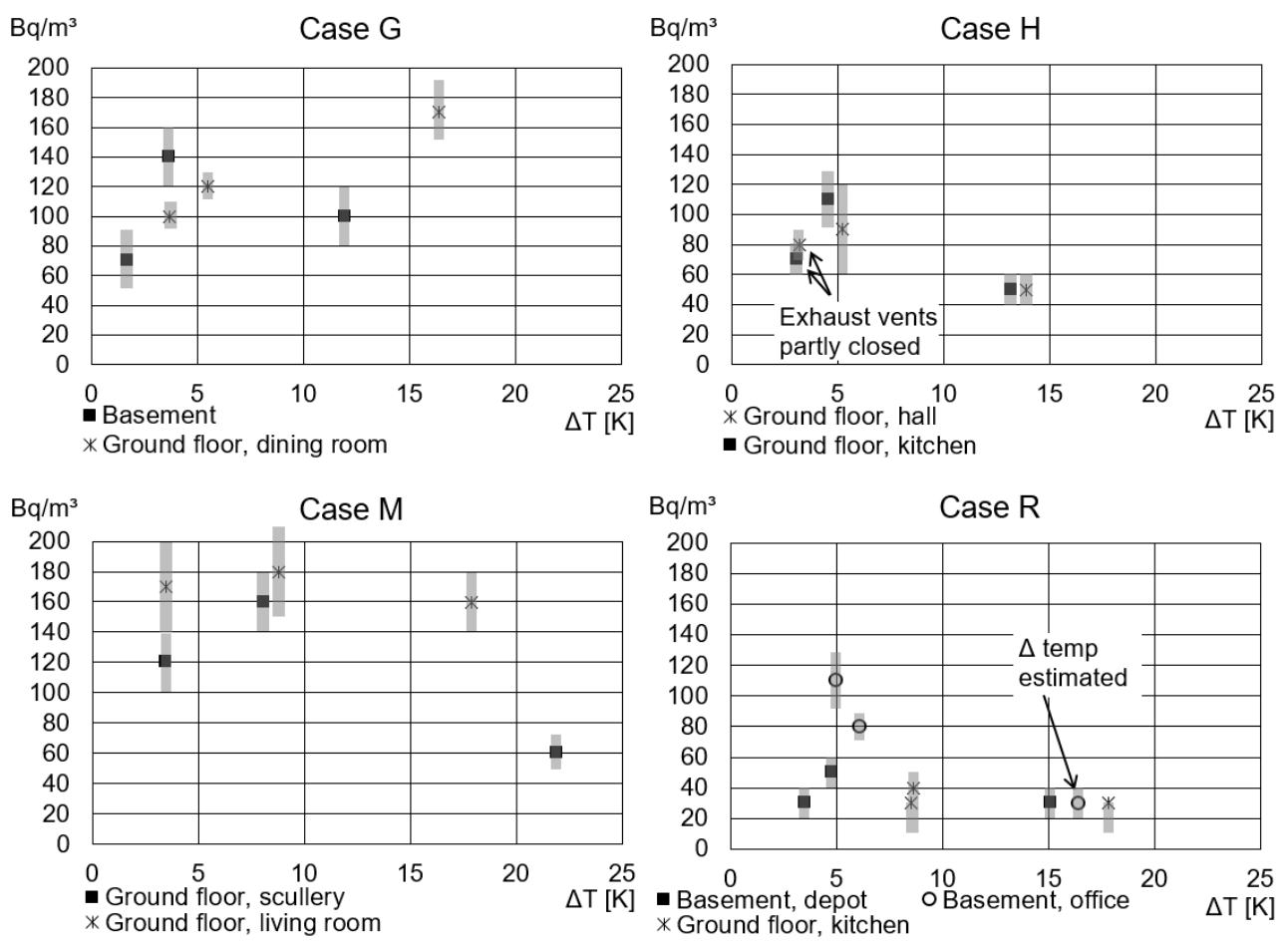

Fig. 3. The graphs show for each case study the average concentration of radon in the indoor air $\left[\mathrm{Bq} / \mathrm{m}^{3}\right]$ over the average temperature difference $[\mathrm{K}]$ for each period. The grey shades indicate the uncertainty of the laboratory radon analysis.

In case study $H$ the ventilation system had been partly closed during the 2 . period, thus the radon level in case study $\mathrm{H}$ in this period is uncertain. In case study $\mathrm{R}$ the temperature in the basements measurement point in the deposit room was not logged. As temperature 
measurements from the basements measurement point in the office were available, the average indoor temperature in the deposit room was estimated.

\section{Discussion}

It was anticipated, that the systems to reduce the indoor radon level based on thermal buoyancy by exploiting the difference between the indoor- and the outdoor temperature are most effective in the heating season, but vary through the year with a risk of less effectiveness out of the heating season. The relation between the average concentration of radon in the indoor air and the difference between the average indoor- and outdoor temperature were shown in the graphs of Figure 3.

In the basement of case study $G$ results show no correlation. In the living room on the ground floor the radon level increased with increasing difference between the indoor- and the outdoor temperature. This followed the general principle of a higher radon level indoor in the heating season. The overall reduction of the average radon concentration in the basement can be a result of other actions, as not only a dilution system had been installed. The basement had also been separated from the $2 \frac{1}{2}$ stories high stairwell, thus the pressure reduction over the ground slab in the basement due to thermal buoyancy was reduced as well.

Results from case study $\mathrm{H}$ show a correlation between low radon levels and a large difference between the indoor- and the outdoor temperature. The results from one of the periods with little temperature difference between the indoor- and the outdoor air (outside the heating season) were uncertain, because of an irregularity in the ventilation setup. Here the variation of the radon concentration was little. Thus, this case was consistent with the anticipation, but did not unambiguously confirm it.

In case study $M$ the results from the scullery and the living room were clearly different. The radon level in the scullery was lower in periods with great difference between the indoor- and the outdoor temperature, which confirms the anticipation. In the living room the radon level was to consider to be equal, regardless the temperature difference. In combination with the fact, that the radon level in the living room was not lower than before the installation of the suction system, this strongly indicated, that the suction system in the living room had no effect or did not create a suction, lowering the air pressure under the slab.

The temperature in the office in the basement of case study $\mathrm{R}$ was estimated, causing extra uncertainty for these results. However, the correlation between a low radon level and a large difference between the indoor- and the outdoor temperature was significant, which confirms the anticipation. For the other two locations the level of radon was, since the installation of the dilution system, very low. They were close to the level of background radon concentration in Danish houses, which is approximately $15-25 \mathrm{~Bq} / \mathrm{m}^{3}$ [1]. At the same time, the radon levels were very close to the detection limit $\left(30 \mathrm{~Bq} / \mathrm{m}^{3}\right)$ of the selected radon measurement method. The results of these measurement points showed a good effect of the measures implemented to reduce the radon level indoors, but cannot be used to evaluate the correlation between radon levels indoor and the temperature difference between the indoor- and the outdoor air.

\section{Conclusions}

Naturally driven dilution or suction systems are based on thermal buoyancy by exploiting the difference between the indoor- and the outdoor temperature to lower radon levels indoor, expecting, that higher temperature differences cause lower concentration of 
radon indoor. This lead to the anticipation, that the systems effect is seasonal - more precisely, that their effect is best in heating season and less effective outside heating season.

Four case studies in single-family houses facilitated measurements from rooms located in either the basement or rooms on the ground floor of houses without cellar. Results show, for a case with both a naturally driven dilution and suction system (case study R), a strong correlation between a low average radon concentration and a high average temperature difference between the indoor- and the outdoor air; indoor temperature higher than outdoor temperature. In another case, one with a suction system (case study $\mathrm{M}$ ), a reduction of the radon level in the indoor air before and after installation of the system was only seen in one out of two locations with measurement points. In the location, where a reduction of the indoor radon level was seen, a strong correlation between a low average radon concentration and a high average temperature difference between the indoor- and the outdoor air was seen, while no such correlation was seen in the other location.

Most likely, the chimney effect, initiated by a sufficient temperature difference between the indoor- and the outdoor air, can drive dilution and suction systems. Without this driving force, i.e. with a temperature difference too small, an increase in the average indoor radon concentration was seen.

In a third case study, equipped with a dilution system (case study $\mathrm{H}$ ), the results showed a tendency of the same pattern. But due to an irregularity in the setup of the dilution system in one of the measurement periods, these results do not unambiguously confirm the pattern. In the last case study, also with a dilution system (case study $G$ ), no correlation was seen.

The correlation of a low indoor radon level and a large temperature difference between the indoor- and the outdoor air in rooms with a slab on ground leads to two conclusions:

1. Naturally driven dilution or suction systems based on the chimney effect can be used to reduce the indoor radon levels. However, the effect of these systems is limited in periods with a little temperature difference between the indoor- and the outdoor air. Thus, the effect is highest in the heating season and least in summer.

2. The limited driving force outside the heating season, requires to be taken into account when controlling/documenting the effect of naturally driven dilution or suction systems on indoor radon levels given as a mean year value. On the basis of this investigation, we recommend measurements to take place over a period of 12 months for determination of the mean year value of the indoor radon level in houses with these systems. Measurements of the radon concentration in the indoor air over shorter periods will deliver results, which depend on the temperature difference between the indoor- and the outdoor air within the measuring period. Such measures will not return a valid value of the mean year value of the indoor radon level for a house with a naturally driven dilution or suction system based on the chimney effect. Following the commonly recommended control/documentation advises of measuring the mean year value of the radon concentration to take place over two months in the heating season [1] will in a house with these systems have the risk of returning an unrealistic low radon level for the indoor air.

This investigation has been supported by InnoBYG, a Danish innovation network for sustainable construction, executed and published in 2016 [3]. Thanks to the building owners to provide the necessary information and field data. 


\section{References}

1. T.V. Rasmussen, SBi-anvisning 247, Radonsikring af eksisterende bygninger (2016)

2. T.V. Rasmussen, SBi-anvisning 270, Måling af Radon i bygninger (2018)

3. B.H. Høegh, T.V. Rasmussen, Effektivitet af naturligt drevne radontiltag året rundt (2016) https://www.innobyg.dk/media/74936/slutrapport-radon_spireprojekt rev.pdf 